\title{
Need, Benefits and Bioethical issues in Online education during COVID-19 Pandemic: a health science student's perspective
}

\author{
Ayush Anand ${ }^{1}$, Ashwini Gupta ${ }^{2}$ \\ ${ }^{1} 4^{\text {th }}$ year MBBS Student and Head, Student's Bioethics Wing, \\ ${ }^{2} 4^{\text {th }}$ year MBBS Student and Member, Student's Bioethics Wing, \\ B. P. Koirala Institute of Health Sciences, Dharan, Nepal \\ Corresponding Author: Ayush Anand \\ E-mail: ayushanandjha@gmail.com
}

\begin{abstract}
Introduction
COVID-19 Pandemic has led to closure of medical schools and academic activities have been withheld leading to delay in various courses and postponement of exams. This situation demands introduction of new modality of teaching for distant education in medical school to reduce the academic burden. This was done using online education platforms like 'Dudal' and 'Zoom'. Our intent is not to provide solutions, but to understand the needs, benefits AND bioethical issues surrounding online education platforms in a health science institution which will help in shaping opinions of students, teachers and administration so as to meet the best needs and provide education without compromising on ethical viewpoint.
\end{abstract}

\section{What is Online education?}

Online education is defined as "education being delivered in an online environment through the use of the internet for teaching and learning. This includes online learning on the part of the students that is not dependent on their physical or virtual co-location. The teaching content is delivered online and the instructors develop teaching modules that enhance learning and interactivity in the synchronous or asynchronous environment" [1]. In my institution, online education platforms used were Dudal and Zoom.

Why sudden need of online education platforms in medical school in wake of COVID-19 Pandemic?

Due to increasing COVID-19 cases government felt the need for strict measure to control infection. As a result, lockdown was introduced throughout Nepal. In accordance with this, medical colleges were also closed and students were asked to return to their home. Medical colleges in Nepal mainly comprise of students from India and Nepal. With rising cases in both countries, re-opening of medical colleges seems to be a distant possibility. Also, borders are closed and no one is allowed to cross. Even if students are allowed to come to their respective colleges, gathering of students in classrooms and wards will expose them to further risk of infection. This could prove very detrimental. Also, no one can say for sure when this pandemic is going to be over. This led to question, till how long will the teaching be suspended? As withholding classes for long would lead to huge academic burden on both college administration and students, introduction of a new modality of education in the form of online education platforms was thought of. 


\section{Factors affecting the choice of online education platforms}

Before the start of classes using online-education platforms, college administration tried to evaluate various factors such as service provider, cost and availability of cellular data/ Wi-Fi, network connectivity, network speed, location of students, liberty to re-attend the classes even if it gets missed in the first place, limitation of various platforms and interaction between teachers and students. These factors were taken into consideration and opinion of students was sought through various meetings. After a lot of mulling over, Dudal and Zoom were finalized.

\section{Benefits and Drawbacks of Online education platforms}

Dudal platform was chosen to conduct remaining theory classes. This proved to be a good platform to allow students from remote areas to access it even with slow network speed. Also, students were able to access classes later on for review or in case they were not able to connect during the scheduled timing. But, learning through this medium was limited. The major issue being not able to ask questions directly instead students had to type the questions and wait for the teacher to see it and then only they could get the answers. Also, teachers were not able to see the students, which led to lesser bonding during lectures. The teachers usually enquired whether we were syncing with them or not, because they felt as if they were teaching their computer screens and not the students per say.

Importance of a good diagram is a must in learning medicine. Not being able to use pointer as used in the Lecture Theatres, posed a challenge for the teachers to explain and the students to understand. This led to fewer interactions between the students and teachers and became of a more one-way flow of information, as it was clearly evident that even if the teacher took an extra step to disseminate the information, we, as students, would definitely not meet them even half way!

Despite Dudal being designed for less network speed, many times there were problems in internet connection due to server problems. This further limited the efficacy of education provided to students. We had to wait for minutes before the class actually started. We would thank our stars if the class ended without any interruption because it was usually inevitable. The rhythm of the class would get broken and the attention and concentration for understanding the concepts were sacrificed.

Zoom was another platform used for online seminars. This required better connection to access, but it was necessary to allow students to conduct online seminars. Zoom provided with better picture visualization leading to better learning. Students were able to use tools such as highlighter and pointer which added multi-dimensional approach to learning. But many students from remote areas found it difficult to access as it required more data and better network speed, meaning more money in an already crisis situation.

Despite trying their best, network issues caused classes to be prolonged, delayed and rescheduled again and again. This proved to be very distressful to both student and teachers. Not many students seemed interested in attending lectures because of these issues. Both these platforms have limitation as they could never be an alternative to hands on experience during clinical posting in wards and OPDs.

\section{Bioethical Issues Surrounding Online education}

\section{Is it accessible to all?}

Online modality of education was introduced considering availability of internet connection to all. But this was not the actual scenario. Even if students had access to internet, many of them faced connection problems. This made access to these education platforms limited. This has led to violation of bioethical principle of equality.

\section{Are students trained for online education?}

Most of the students are not trained for online education platforms. This raises question about the information shared and its actual benefit to students. Because of this ethical principle of beneficence has been put to test. It would have been better if some training course was organized, especially for students in order to help them get maximum out of online classes. 


\section{Privacy, confidentiality and Non-maleficence in online education}

College administration is storing Name, Roll no., Email id and IP addresses of the students. Also, on zoom the whole of the class was being recorded and stored. This stored sensitive data if leaked can have negative impact on health of both students and teachers.

In medical education, sensitive information is discussed which is not meant for general public to see. This can be abused by private or public institutions. There were many instances of unknown people logging in to Dudal using names of students, and mocking the students and teachers and sometimes typing vulgar comments. This is a form of online bullying and harassment and was reported to concerned authorities. On Zoom, usually there was no unauthorized access. Yet there were cases of students receiving threats via email. This means that the hackers got access to the information which was supposed to be kept confidential. All of this denote breach in privacy and confidentiality. Though the administration was doing their best, the principle of Non-maleficence is being put to test indirectly. Serious questions were being raised regarding the security of all data being stored on these platforms. It is the responsibility of college administration to safeguard privacy and confidentiality of students and teachers, and clearly more efforts are needed.

\section{Economic Burden due to online education}

As students need to use these platforms for about 2 to 3 hours daily, access to online education platform led to extra economic burden for students. In contrast to India, Internet connection is costly in Nepal. So, students especially in Nepal had to shed extra dollars for online education. Especially, students from low socio-economic status are at disadvantage. This raises a serious ethical question on our social responsibility. Is it not our responsibility to protect the vulnerable and disadvantaged in difficult times?

\section{Is online education promoting equality, equity, and respect to diversity and pluralism?}

Still there seems to be no substitute for face to face classroom education. In health science education, quite often there is need to demonstrate a process to the students in order for them to understand. Social connection is very crucial for improving instructional effectiveness and building a sense of community [2]. For some students, lower level of social interaction and bonding might make them feel less interested in the course content. Also, different students have different ways of learning. This education modality has put a limitation to learning by audio-visual way and is not in accordance with principles of equality and equity. Bioethical principles of respect to diversity and pluralism have been put to test, thus making them more of platforms where students need to conform.

\section{Does this do justice to its goal of reducing academic burden?}

This style of learning has helped in reducing time of session as compared to all classes being conducted in college itself. But there is an area of concern regarding the efficacy of online learning for health science students. These platforms can never be a substitute to clinical postings. Also, the fact that there will be increased burden on students to complete the clinical postings in quick time will put more pressure on already stressful life of health science students. Theory and practical education are supposed to go side-by-side for consolidation. The fact that our theory classes have been completed and we are having a long gap before the practical are resumed keeps us at an edge as it will require much more effort for the same amount of learning.

\section{Unethical behavior by students?}

Dudal does not provide regulation for unethical behavior by students. Anyone can log in, which can lead to online bullying and harassment. Zoom provides better control over the viewers in this regard but the security issue is still a major concern.

\section{Conclusions}

In COVID-19 pandemic, online education platforms have become main modality of medical education throughout the world and in Nepal. The introduction of online education platform is the need of the hour and no alternate modalities have been observed. This dependence on single 
platform has led to debate on the bioethical issues surrounding the online education platforms. In this article we reflected on some general issues arising from use of these modalities. There were instances of breach in equality and equity. Also, the economic burden on vulnerable population raises questions on our responsibility to protect the vulnerable. The extent to which these platforms promote diversity and pluralism is a matter of debate. Moreover, the modality in use is no substitute to face to face classroom interaction and clinical postings, raising questions on beneficence. All these lead to ethical dilemma on whether or not to continue with these education platforms. Despite of all this, online education seems to be the last resort till the COVID-19 cases begin to decrease and classes can be resumed. So, we need to strengthen the learning process by addressing the bioethical issues.

\section{REFERENCES}

1. Singh V, Thurman A. How Many Ways Can We Define Online Learning? A Systematic Literature Review of Definitions of Online Learning (1988-2018), Am J Distance Educ 2019;33(4):289-306.

2. Aragon SR. Creating social presence in online environments. New Dir Adult Contin Educ 2003;100:57-68.

Acknowledgements: Nil

Funding: Nil

Conflict of interest: $N$ il 